\title{
Cultural Criminology and Gender Consciousness: Moving Feminist Theory From Margin to Center
}

Feminist Criminology 20I6, Vol. I I (4) 354-374

(C) The Author(s) 2016

Reprints and permissions: sagepub.com/journalsPermissions.nav DOI: $10.1177 / 1557085$ II6660609 fcx.sagepub.com

$\Theta S A G E$

\section{Laura Naegler' and Sara Salman²}

\begin{abstract}
Cultural criminology emerged in the mid-nineties with defining texts written by Jock Young, Keith Hayward, and Jeff Ferrell, among others. Since its inception, it has been criticized for its shallow connections with feminist theory. While in theory cultural criminology clearly acknowledges the influence of feminist scholarship, it has in practice often only superficially 'added' on gender and sexuality to its scholarly investigations. Yet, as we argue, research identified with cultural criminology has much to gain from feminist theory. This article reviews a range of cultural criminological scholarship, particularly studies of subcultures, edgework, and terrorism. We investigate three themes significant for feminist research: masculinities and femininities, sexual attraction and sexualities, and intersectionality. Such themes, if better incorporated, would strengthen cultural criminology by increasing the explanatory power of resulting analyses. We conclude by advocating that feminist ideas be routinely integrated into cultural criminological research.
\end{abstract}

\section{Keywords}

cultural criminology, feminist criminology, feminist criminology scholarship, gender and sexuality, edgework, terrorism

One of the main criticisms of cultural criminology, persistent since its inception, is that this perspective pays insufficient analytical attention to the politics of gender. In response, founders of the field have noted that cultural criminology has much in common with feminist criminology (Ferrell, Hayward, \& Young, 2015; Hayward, 2016). Cultural

\footnotetext{
'University of Liverpool in Singapore, Singapore

${ }^{2}$ City University of New York, New York, USA

\section{Corresponding Author:}

Sara Salman, City University of New York, New York, NY 10016, USA.

Email: ssalman@gc.cuny.edu
} 
criminologists also refer to the strong impact of feminist methodologies on the methods of cultural criminology, including the notion of criminological verstehen (Kane, 1998). But while clearly acknowledging the influence of feminist scholarship, gender often seems too superficially "added on" to cultural criminology, a perspective intellectually inspired more passionately elsewhere as it unfolded from the 1990s through the present. If so, what can be learned post facto from feminist theory that can constructively add to the theoretical reach of this criminological "cultural turn"? How can we move gender analysis from margin to center, a phrase that borrows from bell hooks's (1984) wellknown critique of racism's marginalization over the course of theorizing gender?

In this article, we begin with an overview of why gender matters more for cultural criminology than has usually been acknowledged. We review cultural criminological work, focusing on research that engages with feminist theory and on case studies of varied subcultures, edgework, and terrorism. We identify three themes - the study of masculinities and femininities, sexuality, and intersectionality-which, if better incorporated, would strengthen cultural criminology and increase the explanatory power of resulting analyses. Finally, we conclude by discussing the implications of this analysis for the future of cultural criminology and the study of gender within criminology overall.

\section{Why Gender Matters}

The rise of cultural criminology occurred through the 1990s when in sociology-with which criminology in the U.S. academy is closely intertwined-a cultural turn was likewise for years afoot. Culture had become hugely significant for French theorists from Foucault to Bourdieu, Lacan, and Derrida; in the United States, the culture section of the American Sociological Association (ASA) grew to be one of the largest within the organization. Culture, of course, mediates between agencies and structures, and its association with a wide range of practices and institutions of everyday lifeneighborhood and communities, media, religion, ethnic and racial group affiliations, language, customs - was plumbed both for its own significance and for its complex influence on the reproduction of neoliberalizing global capitalism. Within criminology, the publication of Jack Katz's (1988) The Seductions of Crime was one incarnation of this broader cultural turn. Katz's now-classic work introduced "foreground" factors that have been relatively ignored in favor of "background" structural analyses, brilliantly focusing on the roles of emotions and phenomenological immediacy and contingency to illuminate why "criminal/ized" events may (or may not) occur.

Katz's work similarly influenced the interdisciplinary orientation of cultural criminology. Since the perspective's inception in 1995 with Ferrell and Sanders's Cultural Criminology, it has focused on the cultural meanings of practices defined as "crime" and the cultural dynamics of criminalization and control for the late modern condition. Here, culture is understood as the "symbolic environment" (Ferrell et al., 2015, p. 3) in and through which individuals and groups make sense of their being, their actions, and the social and material world. "Culture" is inextricably intertwined with structures of power and shaped by existing patterns of inequality, but it is not seen as a static entity reducible to class, ethnicity, or territory. Rather, for cultural criminologists, culture is 
dynamic. A complex interplay of transgression, criminalization, and control lies at the core of the continuous and often paradoxical processes by which meaning and identities are negotiated and generated. "Crime" is not simply the act of deviating from a social norm, but relates to a wide assortment of institutions that engage in the production and circulation of cultural meanings that shape perceptions of crime. Consequently, transgression and crime are social products meaningful within the specific cultural dynamics surrounding them and "must be read in terms of the meanings they carry" (Hayward \& Young, 2004, p. 259).

Following this perspective on crime and culture, cultural criminology emphasizes human agency and the distinctive creativity of human action and practices. Moreover, crucial for cultural criminology, human actions and experiences have to be understood in the context of economic globalization, the rise of neoliberal ideologies, and increasing economic insecurity. As Young (1999) argues with his concept of the bulimic society (see also Brotherton \& Naegler, 2014), these features of late modernity incessantly create new categories of inclusion and exclusion. Widespread experiences of "ontological insecurity" pervade late modernity; individuals are disembedded from biography, and discontinuities of individual narratives result (Young, 2007).

Then too, in Young's understanding of culture, social conditions cannot be seen as deterministic nor human actions entirely determined by structures (Young, 2007). Rather, collective meaning is generated through fluid interactive processes; connotations, definitions, rules, and values are constantly negotiated and can be maintained and enforced as well as discarded, reshaped, or resisted (see also Salman, 2014). Furthermore, people cope in multiple ways with emotions evoked by intensified conditions of insecurity and seemingly endless, spiraling social changes; they find and invent new ways to reassert identity (Hayward, 2004). Thus, a richly diverse and creative set of human practices confirm the centrality of culture for understanding both social life in general and crime in particular.

But the resulting "combination" of culture and crime seems to overlook the role of another important mediating cultural influence on everyday life: gender. Returning to Simone de Beauvoir's (1953) seminal The Second Sex, it is clear that the binary of masculinity and femininity is one-if not the primary-cultural distinction foisted onto human beings from birth. Applied to criminology, this helps to connect genderbased dichotomies in emotion and expression - for example, inclinations toward "active" or "passive" poses, and toward internalized or "acted out" angers — with analogously gender-skewed patterns in crime commission and punishment. In her systematic study, Eileen Leonard (1981) found many criminological theories could not adequately explain gender differences in the rates and types of crimes committed. She thus aruged that good criminlogical theory ought to be able to explain gender disparities in who commits crime and why.

This brings us to our main purpose here: Why and how does gender matter for cultural criminology? The significance of gender as a core axis of both experience and understanding does not appear to have been deeply incorporated into cultural criminology's basic analytic framework at the outset. As we show, gender analysis has tended to appear at the "margins" rather than as a core element in many works of cultural criminology despite this perspective's other major theoretical strengths. 
Moreover, cultural criminology has been inclined to treat "masculinized" activities as its main events - thereafter bringing in women (and feminist analyses) mostly when women seem to be involved with what could be called "male-dominated" cultural activities such as edgework or terrorism. But certainly women can and do engage in "criminal" cultural activities that do not simply resemble or mimic the kinds of activities engaged in and studied by men. This is one line of inquiry cultural criminology can and should pursue, but it is only one of many possible avenues that gender-cognizant research on crime and culture could advance.

Given the intellectual context we have sketched, let us turn now to three themes culled from de Beauvoir (1953), Butler (1990), hooks (1981, 1984), and Collins (2002), among other feminist theorists in and outside of sociology and criminology. These themes may be useful for expanding cultural criminology's theoretical reach through a widened "gender" lens. The first theme involves how and where both masculinity and femininity, in their various iterations, figure into cultural criminological analyses. Do ideologies of masculinity affect motivations for crime - and, if so, has this tended to be acknowledged or overlooked in extant cultural criminological research? Moreover, when the influence of masculinities as adopted/imposed ideology is acknowledged, how are particular emotional expressions enabled or blocked? This focus on masculinity's influence has appeared in some criminological research like the work of James Messerschmidt (2014) but has less actively figured in well-known cultural criminological writings per se. In ensuing sections we focus on the implication of gender analyses for studying cultural criminology.

A second theme culled from feminist theory involves the influence on human behavior and practices of sexuality: Exploring sex has also tended to be overlooked in research on the "traditional" topics of cultural criminology, from terrorism through edgework and other subcultural activities in which both men and women participate. Feminist theorists have long diagnosed gender as a form of dominance/subordination that relies for its power on exerting control over women's (and people's) bodies; such controls can be part of culture and its mediations. But greater attention to sexuality within cultural criminology also suggests paying close attention to sexualities' pleasures as well as dangers, that is, exploring how everyday experiences of desire and attraction often motivate people across genders toward or away from crime.

Last but just as significantly, a third theme taken from feminist theory involves the importance of intersectional analyses. Here, we explore how multiple factors including gender, race, and class can theoretically expand a "feminist cultural" criminology. Feminist theorists increasingly insist on recognizing how racialization and class discrimination profoundly affect cultural life experiences. Such overlapping biases often contribute to the maintenance of a gendered and heteronormative social order (e.g., Davis, 2008; Jackson, 2005). While intersectionality at times seems to be at risk of being reduced to a buzzword, it offers a refinement of feminist analysis that we consider of major significance for cultural criminology. We now turn toward showing how these three themes help to illuminate cultural criminological research on diverse practices from terrorism to edgework. What insights does and can feminist analysis bring? 


\section{Common Grounds}

Before proceeding, a body of already extant scholarship that indicates growing connections between cultural and feminist criminology needs to be acknowledged. Seal's (2013) research on Western media coverage of the 2012 arrest of the band members of the Russian feminist punk band Pussy Riot is an example of self-identified "feminist cultural criminology." Recognizing the (cultural) criminalization of the band members and their self-conscious use of imagery and style as a cultural criminological case study par excellence, Seal explores the changing meaning of the female protestor in the media as she has been situated in wider geopolitical discourses. Seal draws on Alison Young's (1990) argument in Femininity in Dissent that the female protestor is negatively represented as unruly and shows that this was not the case for the Western media coverage of Pussy Riot and their arrests. Rather than depicting the band members as disruptive, or trivializing or ignoring their outspoken feminism, Seal (2013) argues that Western media painted these women in a predominantly positive light. Central to understanding the positive reception is Pussy Riot's relationship to postCold War Western discourse on Russia. In this context, Russia is depicted as an authoritarian regime repressing political dissent and artistic expression. At the same time, the Western media's support of Pussy Riot allows for a narrative that promotes gender equality as a central value of Western societies (Seal, 2013).

Nonetheless, specifying more precisely what is (or could be) a feminist cultural criminology remains absent in Seal's work. O'Neill's (2010) research on the regulation of sex work in the United Kingdom offers a clarification of feminist cultural criminological analysis. O'Neill's work has two objectives: (a) to develop participatory methodologies of research that produce politically inclusive forms of knowledge in tune with policy questions and (b) to overcome binary thinking that currently dominates feminist debates about sex work. Here, positions that argue for sex work to be reframed as work/labor under capitalist societies are juxtaposed with those emphasizing exploitation of (female) sex workers as victims of patriarchal power relations.

Drawing on the research of Nancy Fraser (2004), O’Neill (2010) argues for the simultaneous recognition of female sex workers' subjectivities and of the material conditions within which they work. In so doing, she combines both feminist and cultural criminological approaches; cultural criminology provides the basis for O'Neill's cultural materialist analysis and informs her participatory and politicized methodological approach. Indeed, O'Neill's treatment of the "historical, cultural, and emotional experiences of the people involved" (p. 219) resonates with Jock Young's (2011) concept of the criminological imagination. O'Neill further argues for the necessity of using the category of intersectionality to provide - without reverting to binary thinking - a comprehensive and refined analysis of how both materiality and redistribution, as well as recognition and identity, profoundly challenge sexual and social inequalities.

The above illustrations from "feminist cultural criminology" show that there are intersections between feminist theory and cultural criminology. Nonetheless, we argue that analytic attention to gender, sexuality, and intersectionality is relatively marginal in the majority of cultural criminological research to date. This tendency reproduces a 
heteronormative masculine lens that paradoxically blunts the potential analytic strength of cultural criminology. To make our argument, we begin by looking at cultural criminological research involving cultural norms of masculinities and femininities.

\section{Masculinities and Femininities}

One of the characteristic features of the cultural criminological perspective is its emphasis on emotion, sensation, and experience. People, cultural criminologists contend, do not solely commit crime out of rational reasons or opportunistic cost-benefit calculations as suggested in more orthodox criminology. They are also motivated by emotional rewards, whether "moments of illicit pleasure" (Ferrell, 1996, p. 316) or other intense emotional experiences of excitement, autonomy, and visceral self-actualization. Exploring these experiences is certainly profound for understanding, in Katz's words, the "seductions of crime." However, there are pitfalls in the cultural criminological take on emotions and experience in criminal activity that become particularly evident when intertwined with questions of masculinity and femininity. It has been a common critique by feminist scholars that cultural criminology, in addition to being overly attuned to certain kinds of crime more frequently enacted by men, endorses (and at times valorizes) a specific cultural ideal of "masculine" activity as found in edgework or subcultural activities wherein men are the predominant actors.

Indeed, cultural criminology has been inclined to treat "masculinized" activities as its main events. This is the result of, and at the same time has resulted in, cultural criminology's tendency to prioritize a certain set of emotions - thrill, excitement, feelings of pride and self-importance, control, and power - that are too quickly and often too uncritically seen as the domain of men. This inclination to perceive "masculinized" activity and experience as the main event is even evident when research is fundamentally about exploring notions of femininity, as, for example, in Alkemade's (2014) analysis of women in the Japanese Yakuza. Alkemade is mostly concerned with investigating women's individual and subjective experiences, emotions and motivations, and how these impact daily experiences within a criminal subculture. Despite this objective, she cautions against the use of "heavily gender-based theories" (p. 13) such as gender equality theories. She argues that such theories tend to overemphasize structure at the expense of agency and alone are insufficient to explain why women participate in organized crime. But this wariness to engage with feminist theory seems curious as the research shows strikingly the highly gendered character of women's daily experience in the male-dominated Yakuza. Indeed, the machismo and hypermasculinity prevalent among the Yakuza men result in seeing women as "insignificant" and "inferior"-if they are seen at all. Women are expected to conform to traditional feminine roles as housewives and caretakers, and to provide reproductive, emotional, and sometimes financial support. However, while the women rarely engage in criminal activity themselves, Alkemade, drawing on Katz, understands their motivations as hardly differing at all from those of the Yakuza men. Deeply fascinated by the thrill and glamor seemingly offered by the Yakuza underworld, women are eventually attracted by the "seductions of crime" and its emotional rewards, even if only engaging in it "by proxy." 
Lured by the Yakuza subculture, women who enter soon find themselves in a situation characterized by marginalization and subordination to the men they come to know within a criminal subculture that is patriarchally organized. Rather than having lives filled with excitement, they face boredom and routine in their lives as housewives confined to the domestic sphere. Consequently, they seek alternative avenues to create a sense of self-control. This happens in a twofold way: first, they develop an "exaggerated sense of self-importance" (p. 84) as expressed in the women's autobiographical accounts, while the "gutting truth" is that they "may be . . not that important after all" (Alkemade, 2014, p. 84). Second, they engage in what Alkemade calls "mimicry." Often against the will of their husbands or male partners, the women adopt traditional and traditionally male yakuza activities; they perform "exclusively male" rituals like getting tattoos. In other words, in reaction to the dominance of men and as an attempt to achieve a sense of control and excitement, the women in the Yakuza act "as men amongst themselves" (p. 84).

Precisely in this argument, though, one can identify a central shortcoming evident in much cultural criminological work: Despite engaging with femininity and masculinity, and gendered relations, Alkemade's analysis never fully sheds its "hegemonic masculine lens." It is left open why women are only able to experience thrill and autonomy by mimicking and "acting like men" rather than through unmediated emotional experiences. The notion of mimicry leaves little space for exploring women's activities, rituals, and subcultural expressions or for investigating emotional experiences possibly independent of, and different from, those felt by men. In addition, it seems difficult to imagine how any criminal organization-let alone one built on closely knit family relations like the Yakuza - could survive without the vast amount of emotional and reproductive work done by women. Yet the analysis renders these traditionally female activities of lesser importance than the activities of men and leaves unquestioned the dependence of the latter on the former. In doing so, it ignores the possibility that the "exaggerated" sense of self-importance stems from women's commitment to a certain ideal of "emphasized femininity" (Connell, 1995).

For our purposes, it may also be useful to ask whether this "masculine lens" is built into some of the very concepts used by cultural criminologists - and whether this potentially skewed lens can be corrected by critically reflecting on cultural mediations of masculinity and femininity and the relation between them. Here, the cultural criminological interest in edgework — voluntary high risk-taking-provides an important case study. The term "edgework" describes acts entwined around the negotiation of a boundary line - of life and death, or danger and safety - actively sought by the edgeworker not for any rational pursuit, but for the very reward of the emotions and sensations they elicit. While "original" edgework mostly involved extreme leisure activities (Lyng, 1990), an intellectual convergence with Katz's phenomenology of crime may have affected cultural criminologists starting to draw attention to the similarities between voluntary high-risk pursuits and the emotional experiences of transgressive acts. Those engaged in crime as "illicit edgework" expose themselves to high risks and develop skills, or the physical and mental abilities, to keep concentration and control in situations characterized by unpredictability and "chaos." They act on the edges of 
safety and danger as much as on those of legality and illegality, engaging in processes of what Lyng calls "moral transcendence" (Lyng, 2005, p. 28) by consciously transgressing rules. In so doing, illicit edgeworkers' phenomenological experience is that of a "controlled sense of loss of control" (Hayward, 2004, p. 163) in a paradoxical situation where the individual feels constantly "at risk"; at the same time, he or she is externally overcontrolled by structural conditions. In other words, illicit edgework is a means to exercise control and autonomy by both symbolically and physically confronting those sources that seemingly deprive the actor of control over his or her own fate.

In cultural criminology, illicit edgework tends to disproportionally take place in what can be seen as "prototypically masculine" high-risk activities (Ferrell et al., 2015 , p. 75) such as graffiti writing or expressive violent crimes. In fact, edgework started as accounting for high-risk pursuits that are, as Lyng (1990) posits in one of his earliest formulations of the concept, "sex-specific" and thus the domain of men. Men's specific attraction to edgework, according to Lyng (1990), stems from their socialization into developing a "skill orientation" (p. 873) that encourages them to use these skills to control their immediate environment. This also explains why women lack an interest in edgework and are less often found among skydivers or BASE jumpers: They are simply not socialized into risk-taking and this particular skill orientation involving exertions of control. Lyng's position on risk-taking is consequently deeply problematic: It equates risk-taking with "simply being male" (Chan \& Rigakos, 2002, p. 750) and reifies binaries of the "active" male and the "passive" female. But far from being averse to them, women take risks - and develop the skill orientation necessary to do so - on a daily basis by virtue of simply being women in patriarchal and misogynistic societies. Women are forced to take risks in the most mundane situations such as walking home alone at night or engaging in intimate relationships that can turn violent. But these are "risks" imposed in different ways, and by the same patriarchal system that leads men into particular risk-taking "attractions"- thus demonstrating the relevance of gender for a deeper understanding of cultural criminological interest in (mostly) men's “edgework."

Moreover, facing threats of domestic abuse, harassment, and sexual assault imposed on them by men, women are held responsible for preventing victimization by means of avoidance and precaution. Every active exposure to risky situations is accompanied by the necessity to negotiate the consequences that come with "victim-blaming" when strategies of risk-management fail (Chan \& Rigakos, 2002; Stanko, 1997). Taking into account women's relational insecurity in patriarchic societies might explain, better than socialization, why the "escapist impulses" of indulgent high-risk pursuits are of less attractive. Voluntary edgework, as feminist scholars have noted (Chan \& Rigakos, 2002; Miller, 1991), is the domain of those holding societal privilege. For women, in particular working-class women and women of color who face risks not by choice but by the mere fact of being women, less of a desire exists to fabricate exceptional risky situations to cope with experiences of alienation, boredom, and ontological insecurity. Again, then, a full understanding of "edgework" and risk-taking pursuits necessitates taking into account the legacies of gender-skewing that go all the way back to de Beauvoir's The Second Sex analysis. 
In Cultural Criminology: An Invitation, Ferrell et al. (2015) respond to such criticisms. They acknowledge the argument that a "masculine" perspective on risk in edgework disregards women's exposure to everyday risks, and distance themselves from the gender-unawareness manifest in early formulations of the concept. They point out that this argument - albeit applying a different explanatory framework - confirms the "sex-specificity" of the concept suggested by Lyng. This is precisely one of the "easy" gender-based dichotomizations that cultural criminology seeks to avoid. Women, they argue, are drawn to extreme, voluntary high-risk pursuits equally and for the same reasons as men: "Both individually and collectively," they "often constitute some of the more skilled and esteemed members of illicit edgework subcultures" (Ferrell et al., 2015 , p. 75). Ferrell et al. continue by contending that edgework allows for understanding gender and gender dynamics, including the considerable numbers of crimes that produce "hegemonic masculinity . . . from a mix of risk taking and embodied masculine emotion, to the detriment of women" (p. 75). These arguments require critical consideration as they seem contradictory at first glance: either edgework is a gender-neutral concept or gender matters when it comes to edgework. The first position suggests that there are no differences between men and women who seek voluntary high-risk pursuits. But, if so, the binary of masculinity and femininity so significant as a cultural influence in most societies from birth is by extension rendered less important, and transposed into one easily neutralized within and by cultural practices. A more persuasive second alternative is that both femininities and masculinities affect why and how women and men engage in edgework as well as how opportunities, expressions, and experiences are shaped. For men, then, the cultural inculcation of masculinities - especially within patriarchal contexts - is likely to have ideological as well as psychosocial consequences for what it means to engage in high-risk pursuits. For women, risk-taking is also likely to be affected in complex ways by gender. Thus, just "adding on" women's risk-taking pursuits to what could be partly characterized as enculturated "masculine" activities - as in Alkemade's analysis of the Yakuza women's activities - risks overlooking that women may engage in edgework in ways which do not simply mimic the kinds of high-risk pursuits engaged in by men.

In fact, cultural criminologists rightly point out that women engage in male-dominated forms of edgework (Naegler, 2014). But what is important to further theorize is that they never do so in the same ways as men. For this reason, we argue that it is not possible to do (and to "do" analyses of) edgework in "gender-neutral" ways - or, for that matter, in disregard of intersections of class, race, and gender. Rather cultural mediations of gender are always there, explicitly or implicitly; they are noticed and experienced by those who engage in edgework, and shape the ways in which people's actions are conceived as well as interpreted. Here, another interesting example is Lois's (2005) research on volunteer search and rescue groups as edgework. Lois shows that male participants were prejudiced against and routinely questioned the physical competence and abilities of their female colleagues; both men and women naturalized "confidence" in risk-taking as the result of testosterone that supposedly made male rescue workers more daring (p. 149). In this setting, then, women adopted a more cautious attitude toward their work and did not experience the same sense of control their 
male peers report - despite the fact that women engaged in the same risky endeavors as men.

Given the impact of cultural mediations of masculinity and femininity, these differing perceptions should not be surprising. As Sandra Walklate (1997) points out, the relationship between men and risk-taking behaviors is widely perceived as positive, while there exists a negative relationship between women and risk. Voluntary risktaking and seeking adventure and power are what men do "normally" (Walklate, 1997, p. 41), while women are held responsible for preventing risks of victimization by taking precautions and not exposing themselves actively to dangers. The concept of edgework, typically placing excitement and control at the center of myriad analyses, could therefore be said to incorporate - albeit unwittingly - the notion of "hegemonic masculinity" (Connell, 1995) by accepting men's risk-taking as part of dominant cultural ideals. As a result, women's high-risk pursuits tend to be subsumed under a masculine, or historically male-dominated, cultural framework; in other words, women who engage in illicit edgework tend to be interpreted as "acting like men" whether in situations where their behavior is condemned or where viewed positively and admired. This has the further effect of rendering female edgeworkers as an exception from a (gendered) norm; their specific experiences may be overlooked precisely because of the dominance of hegemonic notions of "femininity" and "masculinity" in relation to risk.

\section{Sexuality}

A second theme further shows how work in cultural criminology could benefit from according ideas culled from feminist theory. Here, we turn to the role of sexuality in everyday "cultural" life and the extent to which this is often acknowledged, or may be overlooked, in many cultural criminological analyses. Indeed, cultural criminology offers a lens through which behaviors recognized as meaningless or self-destructive can be understood as exciting; it is an approach that accords actors the capacity to derive pleasure from actions otherwise quickly deemed "deviant." Yet many studies within cultural criminology have not sufficiently grappled with questions of sexual desire and attraction as these interact with gender-influenced risk-taking and other meaning-making ventures. Then too, at times, cultural criminologists seem to perceive erotic desires and thrills as identical for men and women rather than investigating culturally gendered differences in how diverse sexualities develop and are experienced.

We begin with the first point (i.e., a tendency to mute and overlook the role of sexualities and attraction) before proceeding to the second (i.e., a tendency to presume sexual experiences to be relatively the same for men and women). The first can be exemplified through cultural criminological accounts of terrorism. In a seminal article on the emotive elements of terror, Cottee and Hayward (2011) offer compelling yet arguably incomplete accounts of the appeal of terrorism. They examine narratives of violence, highlighting excitement and desires for meaning and glory as underpinning motives. But the extent to which erotic desires shape perceptions of what is thrilling and meaningful may be analytically omitted from these authors' narratives, which tend 
to take the actor's gender and sexuality for granted. For example, Cottee and Hayward cite Michael Baumann's autobiographic account of his life as a West German guerrilla, describing how:

He was constantly in motion, always moving from flat to flat and from woman to woman. He did a lot of drugs ... [Never] short of money from all the robberies his group were committing ... (p. 970)

But the fantastical narrative, used to illustrate the emotional underpinnings of political violence, would not explain the seductions of this lifestyle if the actor were anything but a heterosexual man. Baumann desires the freedom to dispose of things, casually making the transition from material goods to women. He depicts a James Bond-like fantasy of wealth, sex, and drugs. Baumann finds thrilling that which signifies an exaggerated masculine ideal: the conspicuous consumption of things, and a casual and objectifying disregard for women, both signs of the successful achievement of manhood. Consequently, Baumann's identity as a heterosexual man informs the emotional basis of his attraction to guerrilla fighting; he is attracted to a lifestyle that allows him to realize an exaggerated heteronormative masculinity, one largely unattainable but nevertheless rendered highly desirable in popular culture.

Furthermore, a disregard for women is contrasted with accounts of love for one's comrades that appear elsewhere in the article and suggest a possibly homoerotic element within the depicted attraction to terror. While Cottee and Hayward (2011) note that love for one's comrades supersedes political or religious motivations among terrorists, they underestimate the extent to which such love can be rooted in men's desires to be with one another:

This sense of fierce commitment to one another [Sebastian] Junger categorizes as a form of love. Not romantic love but the no less charged and encompassing love of comradeship, where every man fights not out of adherence to some abstract idea, but in order to defend his fellow comrade. (p. 977)

Distinguishing "comradely love" from "romantic love" has the effect of preempting investigation into even the possibility that homoerotic feelings may also be afoot. The love felt in battle may not be romantic, but it certainly appears erotic; the wish to die for one's comrades is an intense wish. The men spend significant time together both in and out of battle, forming strong relationships with one another. Moreover, the desires in question are ostensibly desires to be with, if we reference Herbert Marcuse's concept of Eros as the human drive of love (1955/1966). Thus, what Cottee and Hayward (2011) describe, if not romantic, may comprise both homosocial and homoerotic desires to be with, which the men reflect in their expressed willingness to die for each other. The men would rather die than see their comrades (their loved ones) die before them. At least potentially, these may also be expressions of sexuality and desire that deserve deeper analysis especially in relation to how women (and relationships with women) are viewed. For the way the men relate to each other in battle offers a curious 
contrast with the carelessness, the comparative disregard, articulated when they describe their sexual escapades with women; the former emotions seem deeper when contrasted with the relative superficiality of the latter. It would seem, then, that cultural criminology could gain from feminist theories about sexuality (and sexualities) which offer a more multidimensional analytic framework by which to explain what may be attractive about terrorism for the heterosexual men the article studies.

But another issue also arises with regard to cultural criminology's ability to multidimensionally analyze terror: What about women terrorists and their motivations? Since 2014, the world has been grappling with the rise of the terrorist group, the Islamic State of Iraq and the Levant (ISIL), specifically with its appeal to young men and women. News media have been unable to understand ISIL's success at recruiting young women, often referring to the recruits as "lured prey" and "fangirls." Part of the difficulty is that some are as young as 16 years of age, that is, adolescent girls with little life experience to guide them. However, the bigger issue is that women of various ages appear ready to leave everything behind to marry an ISIL warrior and keep the mission of ISIL alive. The notion of predation is solely applied to women. Men are either predators or active participants who join ISIL because of its millennial ideology, its promises of glory, and its encouragement of enslavement and rape of non-Muslim women. What eludes media analysis, reflecting cultural reluctance to recognize the agency of female desire, is that sexuality appears central to ISIL's recruitment both for men and women. For women, ISIL glorifies the notion of marrying a warrior, referring to ISIL women as "mothers of believers"; it offers women a pseudofeminist narrative of autonomy from the meek authority of clerics and even parents. Finally and simply, marriage to an ISIL warrior offers women a chance to experience sex.

Unfortunately, not just the media but cultural criminology has also generally overlooked this possibly sexual dimension of ISIL's attractions for women. In popular publications, Cottee vacillates between describing ISIL women as "fangirls" who are infatuated with ISIL warriors (2015) and rejecting the notion that ISIL women are "fangirls" who are seduced by ISIL boys (2016). Neither position, though, treats women's sexual desires as potential motivation. In the first instance, referring to young women as "fangirls" obscures what may be desires for (and curiosity about) sex as well as hopes of autonomy from parental and community control. By portraying women as relatively passive, this also overlooks reports based on interviews with defected ISIL women suggesting that they sometimes play a significant role in the nonmilitant wings of ISIL (i.e., in both the morality brigade and the sex-slave trade that are central to ISIL's success, see Speckhard \& Yayla, 2015).

The other characterization - that the women are simply fiercely committed to the ideology of ISIL - is also problematic insofar as it fails to allow that women can be "seduced" by something without becoming hapless and losing their agency. Indeed, cultural criminological accounts of terrorism recognize that men who engage in terrorism are motivated primarily by immediate goals like living out a fantastic lifestyle of thrill and excitement, or dying for each other in battle (Cottee \& Hayward, 2011); these accounts characterize men as actively rather than passively "seduced." But if men can be seduced by glory, material things, and sex without giving up their agency, 
women can also be seduced by glory, material things, and sex without becoming passive "lured" prey. In other words, one should not dismiss the notion that women join ISIL as wives of fighters who seek love and companionship in marriage. They believe in the ideology of ISIL, but they are also seduced by the immediate prospect of autonomy, power, and romantic relations. In a New York Times report, women who defected from the group openly talked about enjoying power and the fear they struck in their communities as they led the morality brigade and imposed codes of modesty on other women. This suggested both a desire for traditional gender roles provided by marriage and pleasure in exercising power over other women. Some lamented of soon losing the excitement of love and sex and expressed sadness over their husbands' deaths in suicide missions (Moaveni, 2015).

Overall, then, Cottee's analysis (2016) overlooks the extent to which both masculine and feminine gender ideals shape young people's desires to join ISIL while underestimating the extent to which women can and are agents of their own sexualities. Desiring sex does not reduce women to lured prey, nor does it necessarily take away from their ideological commitment to the group's mission. Rather - as may be a point from feminist theory important to recognize in and beyond cultural criminologysexuality functions as a major motivation for men and women (see Reich, 2012). But what about the second respect in which cultural criminology has not fully incorporated understandings of sexuality - this one not so much a tendency to mute and overlook the role of sex and attraction but to presume that sexualities are similar rather than possibly different across genders?

Concerning the second point, let us turn to Gailey's (2009) research on women's engagement in the pro-ana community. Gailey describes a (mostly) virtual community that interprets anorexia and bulimia as "female edgework," that is, as voluntary choices of lifestyle made by young, predominantly White middle-class women who push themselves to the edges of life and death within this community. In so doing, they experience corporeal sensations and intense emotions described as fulfilling, as well as a sense of autonomy in their everyday lives. Gailey argues that these pro-ana women construct their activities in terms of choices that, in turn, challenge gendered stereotypes of feminine passivity (p. 106).

As Gailey emphasizes, understanding the young women's activities as edgework rather than falling back on pathologizing perspectives about eating disorders qua mental illness allows for taking women's agency into account. She concludes that, therefore, edgework cannot be considered a male-dominated behavior because women engage in edgework similar to men: Their experiences and motivations do not differ qualitatively from the kind of masculine high-risk activities highlighted in cultural criminological accounts. Where gender does make a difference though, she argues, is in responses and reactions-That is, women are more likely than men to become stigmatized when engaging in high-risk pursuits. To be sure, Gailey is correct to note how women's risk-taking endeavors are stigmatized and overlooked. But, more importantly for our purposes here, Gailey's example of female edgework ironically demonstrates that women do not engage in edgework in exactly the same way or for the same reasons as men. Certainly men and women are not ontologically different; however, 
their experiences, accesses, and sometimes motivations are dissimilar precisely because they are subject to different cultural and social expectations and reactions. In this case, women's choices to engage in explicitly "female" edgework result from seeking avenues of emotional self-expression, control, and even the fulfillment of erotic desires otherwise blocked. As Gailey quotes one of her participants describing after starting to fast after "restraint" eating, the visceral experience of starvation holds a distinctly erotic dimension:

But I'll starve myself again, for the sense of power over my body. It's almost an erotic feeling. Feeling better about your body is extremely sensuous. (p. 104)

Gailey insists that the erotic pleasure experienced is same as the thrills sought by graffiti artists and skydivers. Yet this argument does not explain why young women seek erotic experiences that morph into hidden and self-directed violence (and selfdestructiveness). Pro-ana subculture seems to manifest women's desire to experience their sexualities as independent from those of men. But the physical harm self-imposed by pro-ana women reveals something more problematic: For women, whose sexual freedom and sexual expressiveness have historically been blocked and subordinated in male-centric cultures like our own, risk-taking pursuits may be both liberating and internally destructive, rendering pro-ana subculture a violent reaction to a violent culture of control in ways different than men may experience.

Indeed, as Chan and Rigakos (2002) point out, women who seek excitement and erotic pleasure in risky encounters have to negotiate not only risks of physical harm but also a culture hostile to women's sexuality. Women's supposed sexual "promiscuity" is still widely considered deviant; it is publicly shamed and represented as justifications for sexual and physical violence, and too often for rape, enacted by men against women. Thus, female "sexual edgeworkers" are distinct from male "sexual edgeworkers" in that the former must "carefully negotiate the structurally imposed line between ... the Madonna and the whore image" (Chan \& Rigakos, 2002, p. 755). In contrast with men, women often need to adopt additional/extra strategies of risk-management to prevent judgment, negative labeling, condemnation, and violence. Far from being the same as men's edgework, then, women's edgework appears to take place against a different cultural backdrop and within a different context — and, as such may be differently motivated.

\section{Intersectionality}

When it comes to a third theme-intersectionality - it should be noted that efforts have been made within cultural criminology to incorporate this important and relatively recent emphasis in the unfolding of feminist theory. Contemporary feminist theory and research have evolved to the point where studying intersectionality- that is, how gender, sexualities, race/ethnicity, and class discriminations overlap-has become common. Feminist scholars have learned to investigate both women's relative powerlessness in patriarchal societies and interconnections between class, race, and 
gender, that is, multiple and complicated experiences of oppression and domination that are phenomenologically experienced. Nonetheless, within cultural criminology, examples can be found both of scholarship that can gain from a fuller interpretation of intersectionality and of research admirably attentive to interrelated experiences of race, class, gender, and sexual biases.

Returning to research on terrorism, the work of Mark Hamm-while not explicitly using the vocabulary of intersectionality - nonetheless targets the role of class and race in illuminating the rise of White supremacist terrorist groups in the United States. In a 2004 article, Hamm finds that neo-Nazi groups are mostly comprised of young, working-class White men. Some of the young men have witnessed social decay in their communities, thereafter drifting into delinquency; others' lives develop differently. But attraction often occurs when the young men are introduced to a subculture that has a specific style and ethos, triggering "the vitality . . . necessary for skinheads to 'go berserk' on their perceived enemies" (Hamm, 2004, p. 327). Thus, Hamm compellingly makes the connection between being a young White working-class man in a postindustrial society and the appeal of militant White supremacy subcultures. Yet what his analysis overlooks is the extent to which culturally specific expectations of White working-class men leave some, who do not fulfill said expectations, more "vulnerable" than others to the seductions of macho White supremacy. This is where individual differences, including psychosocially unique biographies, become relevant — and where cultural criminological study of terrorism forces us to reckon with the hard fact that those who inflict brutal violence are complicated indeed, and can differ greatly as to how their personal histories mix class and racial factors with biases more specifically related to gender, sexuality as well as personality.

Take Hamm's case study of Peter Langan: It illustrates how an analysis already alive to race and class influences might have further benefited from taking gender, sexuality, and the psychosocial further into account (Hamm, 2004). Langan was the founder of the Aryan Republican Army (ARA) and had a criminal history that included illegal trafficking in firearms and explosives. In 1992, the FBI pursued him for his involvement in a plot to assassinate President George H. Bush (Hamm, 2004). In terms of what C. Wright Mills called personal biography, Langan was born in 1958 to Eugene Langan and Mary Ann McGregor; he was one of six children and soon became his mother's favorite child, receiving "feminine pampering during his formative years" (Hamm, 2004, p. 329). But Hamm does not make clear what he means by "feminine pampering" and what role, if any, this played in generating Langan's delinquency and turn to political violence. Unexplained, Langan's relationship with his mother is woven into the narrative of drifting with the tacit assumption that readers share a singular definition of masculinity such that a "mama's boy" who receives "feminine pampering" needs no further explanation. Presumed is that boys who have too close of a relation with their mothers turn out to be less-than-ideal men: In this case, for instance, Langan was sexually confused, an ARA leader by day and cross-dresser by night (Hamm, 2004).

While there were other factors contributing to Langan's unraveling, Hamm returns to Langan's relationship with his mother. He recounts the Langan family relocating in 1961 to Saigon where Eugene was involved in a political plot to assassinate South 
Vietnam's president Ngô Đình Diệm. The family returned to the United States in 1963 where Langan's French and Vietnamese fluency and appearance made him a target of bullying in school: "Almost overnight, he went from being a pampered mama's boy to being the victim of hate" (Hamm, 2004, p. 330). While the turn to sex, drugs, and rock and roll is in many ways in the 1960s "spirit of the times" (Hamm, 2004, p. 330), there is a persistent hint that Langan's delinquency was linked to the loss of his father, and his "confusion over his newly discovered urge to dress up in his mother's clothing" (Hamm, 2004, p. 330). Hamm's case study is eventually explained in terms of "a crisis in masculinity" whereby Langan turned to White Power to gain the respect of other men (p. 336). Problematically, though, Langan's "crisis" of realizing a specific masculine ideal is left unexplored in the article. In fact, what Langan struggled with is a heteronormative articulation of masculinity, often normalized in White lower-middle and working-class communities, that left Langan a victim of bullying as a child in school and of sexual violence as a young man in prison. Thus, by referring to Langan as a "mama's boy" without exploring the ideological content of this term, Hamm inadvertently reifies the very masculinity that precipitated Langan's crisis. Simultaneously, Hamm's account is left unable to explain with full multidimensionality the biographical narrative he otherwise quite thoroughly explores.

Langan's narrative also suggests other problems that might have been advantageously explored: Not only sexuality but gendered mandates may have been relevant to his case given hegemonic social expectations of child-rearing that may have left him especially vulnerable to violence. As an adult, Langan struggled to live up to rigid codes of gender as well as sexuality that mutually constitute normative masculinity. Moreover, both factors arguably help to explain his attraction to right wing militancy. Langan desired a transgressive and socially stigmatized identity while desiring a repressive social order wherein such differences are flattened. Langan's gender identity crisis in a world hostile to nongender conformists left him alienated and, in turn, susceptible to right wing authoritarianism. A violent macho group appeared, then, as an avenue to relieve the pain of not fitting into the world as well as providing a façade beneath which he could explore his nonconforming desires.

If Hamm's work exemplifies cultural criminological scholarship focused on race and class potentially deepened by greater attention to gender and sexuality-based norms, the work of feminist criminologists such as Eleanor Miller and Valli Rajah — both of whom studied edgework - illustrates research explicitly attuned to gender and sexuality that also integrates sensitivity to racial and class biases women and men face. Both Miller and Rajah illustrate that while much cultural criminological work has not adequately used feminist theory, important exceptions exist. Thus, Miller (1986, 1991), a feminist Marxist and strong critic of Lyng, utilizes the edgework concept in her research on female African American street sex workers who "choose especially risky hustles" (Miller, 1991, p. 1533). As she contends, women involved with high-risk encounters are motivated similarly as Lyng's edgeworkers to seek excitement, adrenaline rushes, and the achievement of a sense of control and autonomy in situations otherwise pervaded by everyday experiences of powerlessness and male objectification. 
Analogously, in her study of poor, drug-using and largely African American and Puerto Rican women who experience habitual domestic abuse by their male partners, Rajah (2007) identifies activities she calls "edgework-resistance." In attempting to rebel against the constraints and patriarchal control of their intimate partners, women overtly and covertly "resist" in borderline zones of safety-and-relative danger; they undertake small acts of defiance and disobedience, aware that they risk physical harm should their partners retaliate violently. Acts of edgework-resistance thus draw on "context-specific" knowledge such as partner's habits, weaknesses, strengths, dislikes, and/ or probable reactions; if accomplished successfully, such acts provide for "embodied rewards" (Rajah, 2007, p. 201) like experiences of autonomy and self-determination.

Both Rajah and Miller show that by engaging in edgework, women use agency in eliciting emotional pursuits and visceral pleasures within situations marked by their relative powerlessness; these situations thereby allow for enactments of control. However, women who engage in edgework are not simply "mimicking" men, as in the critique presented above, but develop specific social practices shaped by the combination of their multiple, "intersectional" experiences of oppression. This can result in women's resistance to one specific form of oppression all the while their practices are subtly reproducing another. As Rajah points out, the women in her study are forced to negotiate between resistance and financial dependency to their male partners, and between cultural imperatives that assign responsibility to women for preventing domestic abuse while demanding that they maintain the stability of a relationship. By acting in stereotypical feminine ways while high risk-taking, women may contribute to the maintenance of the current gendered social order (analogously to how, in maledominated edgework, masculine gender stereotypes are also reproduced). In addition, Miller emphasizes that the illegal sex work subject of her study is a high-risk situation almost by definition; given dangers of arrest and/or physical violence by men, this is so regardless of whether women seek or avoid risky situations. In both cases, women's edgework is not a "desired choice" but must be understood in the context of structural inequality, economic marginalization, and dependency; without a sense of gender, race, and class intersectionality, both of their case studies would be only partially explanatory. For it is because of multiple overlapping social factors that these examples of women's edgework involve risks that "far exceeds those of working- and middle-class white men" (Miller, 1991, p. 1532). Consequently, edgework practices have very different cultural meanings depending on gender, sexuality, race, and class; while "experimentally and in terms of social psychological impact, edgework might be functionally equivalent across [different societal] groups," the "structures of oppression to which [edgework] responds are unique” (Miller, 1991, pp. 1533-1534).

Such attentiveness to intersections of class, race, and gender in Miller's and Rajah's accounts allows for a necessary refinement of the edgework concept by making visible both women's relative powerlessness in contemporary society and their attempts to control or resist multiple forms of oppression. Men's edgework (and "masculine" edgework) needs to be analyzed with a similarly sophisticated sense of multidimensionality, and with analogous sensitivity to men's experiences of power and powerlessness as both shape their risk-taking pursuits and motivations. 


\section{Discussion}

Cultural criminologists often emphasize this perspective's advantages as a "free intellectual space" for the critique of orthodox criminologies. Indeed, cultural criminology offers progressive analyses and "invitational openness" (Ferrell et al., 2015 , p. 25) that is friendly toward feminist endeavors and critical of male-dominated societies' historical sexism. It is exactly in this spirit that this article has offered an equally friendly critique, calling for gender to become a regular and not "added on" component of cultural criminology's theoretical program and empirical investigations. To date, albeit with some exceptions, cultural criminology has tended to "add on" considerations of gender and sexuality rather than according both key places in its research and scholarly investigations. In turn, however unintentionally, this lack of gender awareness risks mimicking the effects of sexism itself through the unwitting incorporation of a hegemonic, "masculine" analytic lens.

Moreover, the above problem hinders the ability of the perspective to fully grasp the complexity of cultural dynamics as they influence, and are influenced by, also distinctively cultural mediations of gender and sex. While cultural criminology has succeeded in exemplifying Clifford Geertz's concept of thick description, offering detailed accounts of social actors' everyday lives in both ordinary and extraordinary moments, it may have not accorded gender and sexuality their due as these affect the multidimensionality of human practices. This relative overlooking of gender and sex as units of analysis presents a problem given the perspective's intention of elucidating the emotive bases of deviance and transgression. For the attractions of crime cannot be fully explained without accounting for hegemonic codes of femininity and masculinity, and for societal repression of desires and emotions. Thus, while conventional studies of crime and transgression can and should learn from the cultural criminological approach, cultural criminology can enrich its own otherwise rich interpretive powers by moving gender and sex-as objects of analysis-from its margins to its center.

\section{Acknowledgments}

We thank the reviewers for their helpful feedback, Lynn Chancer and Dan Douglas for their editorial suggestions.

\section{Declaration of Conflicting Interests}

The author(s) declared no potential conflicts of interest with respect to the research, authorship, and/or publication of this article.

\section{Funding}

The author(s) received no financial support for the research, authorship, and/or publication of this article. 


\section{References}

Alkemade, R. (2014). Outsiders amongst outsiders. A cultural criminological perspective on the sub-subcultural world of women in the Yakuza underworld. Nijmegen, The Netherlands: Wolf Legal Publishers.

Brotherton, D., \& Naegler, L. (2014). Jock Young and social bulimia: Crime and the contradictions of capitalism. Theoretical Criminology, 18, 441-449.

Butler, J. (1990). Gender trouble: Feminism and the subversion of identity. New York, NY: Routledge.

Chan, W., \& Rigakos, G. S. (2002). Risk, crime and gender. British Journal of Criminology, 42, 743-761.

Collins, P. H. (2002). Black feminist thought: Knowledge, consciousness, and the politics of empowerment. London, England: Routledge.

Connell, R. (1995). Masculinities. Cambridge, UK: Policy Press.

Cottee, S. (2015, December). The challenge of Jihadi Cool. The Atlantic. Available from http:// www.theatlantic.com

Cottee, S. (2016). What ISIS women want. Foreign Policy. Retrieved from http://foreignpolicy. com/2016/05/17/what-isis-women-want-gendered-jihad/

Cottee, S., \& Hayward, K. (2011). Terrorist (E)motives: The existential attractions of terrorism. Studies in Conflict \& Terrorism, 34, 963-986.

Davis, K. (2008). Intersectionality as buzzword. A sociology of science perspective on what makes a feminist theory successful. Feminist Theory, 9, 67-85.

de Beauvoir, S. (1953). The second sex (H. M. Parshley, Trans.). London, England: Jonathan Cape.

Ferrell, J. (1996). Crimes of style. Urban graffiti and the politics of criminality. Boston, MA: Northeastern University Press.

Ferrell, J., Hayward, K., \& Young, J. (2015). Cultural criminology: An invitation (2nd ed.). Los Angeles, CA: SAGE.

Ferrell, J., \& Sanders, C. (1995). Cultural criminology. Boston, MA: Northeastern University Press.

Fraser, N. (2004). Recognition as justice? A proposal for avoiding philosophical schizophrenia. In C. Sinkwan (Ed.), Law, justice, and power. Between reason and will (pp. 139-157). Stanford, CA: Stanford University Press.

Gailey, J. (2009). "Starving is the most fun a girl can have." The pro-ana subculture as edgework. Critical Criminology, 17, 93-108.

Hamm, M. (2004). Apocalyptic violence: The seduction of terrorist subcultures. Theoretical Criminology, 8, 323-339.

Hayward, K. (2004). City limits. Crime, consumer culture and the urban experience. London, England: GlassHouse.

Hayward, K. (2016). Cultural criminology: Script rewrites. Theoretical Criminology, 1-25. Retrieved from http://tcr.sagepub.com/content/early/2016/05/06/1362480615619668

Hayward, K., \& Young, J. (2004). Cultural criminology. Some notes on the script. Theoretical Criminology, 8, 259-273.

Hooks, B. (1981). Ain't I a woman: Black women and feminism. Boston, MA: South End.

Hooks, B. (1984). Feminist theory: From margin to center. Boston, MA: South End.

Jackson, S. (2005). Sexuality, heterosexuality and gender hierarchy: Getting our priorities straight. In C. Ingraham (Ed.), Thinking straight: New work in critical heterosexuality studies (pp. 15-39). New York, NY: Routledge. 
Kane, S. (1998). Reversing the ethnographic gaze: Experiments in cultural criminology. In J. Ferrell \& M. Hamm (Eds.), Ethnography at the edge. Crime, deviance and field research (pp. 132-145). Boston, MA: Northeastern University Press.

Katz, J. (1988). Seductions of crime: Moral and sensual attractions of doing evil. New York, NY: Basic Books.

Leonard, E. (1981). Women, crime and society: A critique of theoretical criminology. New York, NY: Longman.

Lois, J. (2005). Gender and emotion management in the stages of edgework. In S. Lyng (Ed.), Edgework. The sociology of risk-taking (pp. 117-152). New York, NY: Routledge.

Lyng, S. (1990). Edgework: A social psychological analysis of voluntary risk taking. The American Journal of Sociology, 95, 851-886.

Lyng, S. (2005). Sociology at the edge: Social theory and voluntary risk taking. In S. Lyng (Ed.), Edgework: The sociology of risk-taking (pp. 17-49). New York, NY: Routledge.

Marcuse, H. (1966). Eros and civilization: A philosophical inquiry into Freud. Boston, MA: Beacon Press. (Original work published 1955)

Messerschmidt, J. (2014). Crime as structured action. Doing masculinities, race, class, sexuality and crime. Plymouth, UK: Rowman \& Littlefield.

Miller, E. (1986). Street woman. Philadelphia, PA: Temple University Press.

Miller, E. (1991). Assessing the risk of inattention to class, race/ethnicity, and gender: Comment on Lyng. The American Journal of Sociology, 96, 1530-1534.

Moaveni, A. (2015, November). ISIS women and enforcers in Syria recount collaboration, anguish and escape. New York Times. Available from http://www.nytimes.com

Naegler, L. (2014). The ritual of insurrection and the "thrill-seeking youth": An instant ethnography of inner-city riots in Germany. In D. Pritchard \& F. Pakes (Eds.), Riot, unrest and protest on the global stage (pp. 151-168). Basingstoke, UK: Palgrave Macmillan.

O'Neill, M. (2010). Cultural criminology and sex work: Resisting regulation through radical democracy and participatory regulation. Journal of Law and Society, 37, 210-232.

Rajah, V. (2007). Resistance as edgework in violent intimate relationships of drug-involved women. British Journal of Criminology, 47, 196-213.

Reich, W. (2012). Sex-pol: Essays, 1929-1934 (L. Baxandall, Ed.). London, England: Verso.

Salman, S. (2014). Troubling the psychosocial: Jock Young's late modern subjectivity from Sartre to Marcuse. Theoretical Criminology, 18, 450-458.

Seal, L. (2013). Pussy riot and feminist criminology: A new "femininity in dissent?" Contemporary Justice Review, 16, 293-303.

Speckhard, A., \& Yayla, A. S. (2015). Eyewitness accounts from recent defectors from Islamic state: Why they joined, what they saw, why they quit. Perspectives on Terrorism, 9, 95-118.

Stanko, E. (1997). Safety talk: Conceptualizing women's risk assessment as a "technology of the soul." Theoretical Criminology, 1, 479-499.

Walklate, S. (1997). Risk and criminal victimization: A modernist dilemma? British Journal of Criminology, 37, 35-45.

Young, A. (1990). Femininity in dissent. London, England: Routledge.

Young, J. (1999). The exclusive society: Social exclusion, crime and difference in late modernity. London, England: SAGE.

Young, J. (2003). Merton with energy, Katz with structure: The sociology of vindictiveness and the criminology of transgression. Theoretical Criminology, 7, 388-414.

Young, J. (2007). The vertigo of late modernity. Los Angeles, CA: SAGE.

Young, J. (2011). The criminological imagination. Cambridge, UK: Polity Press. 


\section{Author Biographies}

Laura Naegler, $\mathrm{PhD}$, is a lecturer in sociology, social policy, and criminology at the University of Liverpool in Singapore. Her research interests are critical and cultural criminology, the study of social movements, social unrest, changing processes of democratization, and "new" forms of democratic participation. She has conducted, among others, critical ethnographic research with the post-Occupy movement in New York City and is author of Gentrification and Resistance (LIT Verlag, Berlin; 2012), a study of antigentrification movements in Hamburg, Germany.

Sara Salman is a PhD candidate in sociology at the Graduate Center, City University of New York. Her dissertation is a comparative study examining citizenship in late modernity. She has conducted ethnographic research in Michigan and New York investigating poverty and displacement, and government assistance programs. She has also written on war and genocide, political unrest in the Middle East, and the influence of existentialism and psychoanalysis on contemporary social theory. 